\title{
Changes in land use alter the structure of bacterial communities in Western Amazon soils
}

\author{
Ederson da C Jesus ${ }^{1,2}$, Terence L Marsh ${ }^{1}$, James M Tiedje ${ }^{1}$ and Fatima $\mathrm{M}$ de S Moreira ${ }^{2}$ \\ ${ }^{1}$ Center for Microbial Ecology, Michigan State University, MI, USA and ${ }^{2}$ Soil Science Department, \\ Universidade Federal de Lavras, Lavras, Minas Gerais, Brazil
}

\begin{abstract}
Here we show how agricultural practices by indigenous peoples as well as forest recovery relate to the structure and composition of Amazon soil bacterial communities. Soil samples were collected in different land use systems and bacterial community composition and diversity were explored by T-RFLP, cloning and sequencing, and data were analyzed with multivariate techniques. The main differences in bacterial community structure were related to changes in the soil attributes that, in turn, were correlated to land use. Community structure changed significantly along gradients of base saturation, $\left[\mathrm{Al}^{3+}\right]$ and $\mathrm{pH}$. The relationship with soil attributes accounted for about $31 \%$ of the variation of the studied communities. Clear differences were observed in community composition as shown by the differential distribution of Proteobacteria, Bacteroidetes, Firmicutes, Acidobacteria and Actinobacteria. Similarity between primary and secondary forest communities indicates the recovery of bacterial community structure during succession. Pasture and crop soil communities were among the most diverse, showing that these land use types did not deplete bacterial diversity under the conditions found in our sites.
\end{abstract}

The ISME Journal (2009) 3, 1004-1011; doi:10.1038/ismej.2009.47; published online 14 May 2009

Subject Category: microbial population and community ecology

Keywords: slash-and-burn agriculture; bacterial diversity; T-RFLP; Amazon

\section{Introduction}

The Amazon is one of the main hot spots of the world's biodiversity, but little is known about the composition of its bacterial communities or about how they are impacted by human activities such as deforestation and agriculture. This is true for tropical regions in general, as few studies have focused on belowground biodiversity (Swift et al., 1998), especially when compared to the attention aboveground diversity has received. Some surveys in the Amazon and other tropical environments report the composition of soil bacterial communities and the effect of land use and forest recovery on their phylogenetic and functional diversity (Borneman and Triplett, 1997; Yin et al., 2000; da Silveira et al., 2006; Pereira et al., 2006; Quirino et al., 2009), but factors possibly causing these changes remain to be determined.

Factors responsible for changes in bacterial communities can include soil type, plant species and land management (Nüsslein and Tiedje, 1999; Wieland et al., 2001; Steenwerth et al., 2002; Buckley

Correspondence: E da C Jesus, 540 Plant and Soil Sciences Bldg, Michigan State University, East Lansing, MI 48824, USA.

E-mail: ederson@msu.edu

Received 5 January 2009; revised 23 March 2009; accepted 27 March 2009; published online 14 May 2009 et al., 2006). Recent papers indicate that soil attributes are important in determining the structure and composition of bacterial communities, as well as affecting function (Hartman et al., 2008; Wakelin et al., 2008). Knowing which factors are related to changes in bacterial communities can provide important information for their management and to assess environmental impact.

Within this context, our main objectives were to (1) assess the composition and diversity of soil bacterial communities in the Western Amazon, (2) identify whether and how cultivation influences the structure of bacterial communities and (3) identify environmental factors linked to differences in the structure and diversity of those communities. We took advantage of the changes in land use implemented by indigenous peoples for evaluating the impact of such changes over a longer time period and as a possible indicator for what might occur from the larger-scale, tropical, land use change now underway.

\section{Materials and methods}

Site description and soil sampling

The study sites are in the Benjamin Constant municipality, Amazonas State, Brazil, between the geographic coordinates $4^{\circ} 21^{\prime}$ and $4^{\circ} 26^{\prime}$ south and 
$69^{\circ} 36^{\prime}$ and $70^{\circ} 1^{\prime}$ west, along the Solimões River (Supplementary Figure S1). The climate in the region is classified as Af (Koppen's classification), with average annual temperature of $25.7^{\circ} \mathrm{C}$ and average precipitation of $2562 \mathrm{~mm}$. Inceptisols is the predominant soil type with Gleysols and Alisols also found (Coelho et al., 2005). The rate of deforestation in this region is low mainly due to the difficulty of access and low population density. Local communities use the land for slash-and-burn agriculture; however, some pasture areas are also present as a consequence of governmental polices implemented during the 1970s.

Twenty-six composited samples were collected from crop, pasture, agroforestry, young secondary forest (up to 5-years old), old secondary forest (5- to 30years old) and primary forest sites in March 2004. All sites were originally highland forest. Species cultivated in the crop sites were cassava, banana, maize, sugarcane and pineapple. Agroforestry sites were cultivated mainly with peach palm (Bactris gasipaes), cupuassu (Theobroma grandiflorum), banana, pineapple and coffee (Fidalgo et al., 2005). Each composite sample was formed by 12 subsamples, collected at a depth of $0-20 \mathrm{~cm}$, within a circle of $6 \mathrm{~m}$ diameter (Supplementary Figure S2), and were submitted to chemical, physical and microbiological analyses. Soil chemical and physical attributes (Supplementary Tables S1 and S2) were analyzed at the Department of Soil Science of the Universidade Federal de Lavras (Brazil) and microbiological analyses were performed at the Center for Microbial Ecology (Michigan State University, USA).

DNA extraction, T-RFLP and sequencing analysis Five grams (dry weight) of soil was used for DNA extraction with the Power Max Soil DNA Isolation Kit (MO BIO Laboratories Inc., Carlsbad, CA, USA), according to the manufacturer's instructions. The $16 \mathrm{~S}$ rRNA gene was amplified with the primers $63 \mathrm{~F}$ labeled with 6-carboxyfluorescein and 1389R (Marchesi et al., 1998; Osborn et al., 2000) in a RoboCycler Gradient 96 PCR machine (Stratagene, La Jolla, CA, USA). Reconditioning PCR reactions were performed in triplicate for each sample (Supplementary material), combined and the PCR products were purified with the Qiagen PCR purification kit (Qiagen, Valencia, CA, USA) after analysis by gel electrophoresis.

Purified PCR products were treated with the Klenow fragment (Egert and Friedrich, 2005) and purified again with the Qiagen PCR purification kit. PCR products (40 ng) were digested with the enzymes MspI and HhaI in 15- $\mu$ l separate reactions, at $37^{\circ} \mathrm{C}$ for $3 \mathrm{~h}$. Digestion reactions were performed in duplicate for each sample. DNA was precipitated overnight. The DNA pellets were resuspended in $9.85 \mu \mathrm{l}$ of deionized formamide and $0.15 \mu \mathrm{l}$ of ROX size standard 15 min before analysis in ABI system analyzer.
Libraries were built for samples from primary forest (GenBank accession no. FJ024502-FJ037063), old secondary forest (GenBank accession no. FJ037064-FJ037232), pasture (GenBank accession no. FJ037233-FJ037389) and crops (GenBank accession no. FJ037390-FJ037544) sites. The same PCR conditions used for terminal restriction fragment length polymorphism (T-RFLP) analysis were used, with the exception that primer 63F was not labeled with FAM. Triplicates were combined and purified with the Qiagen PCR purification kit. Cloning was performed with the TOPO TA Cloning Kit for Sequencing (Qiagen) according to the manufacturer's instructions. Partial sequences with an average length of $760 \mathrm{bp}$ were obtained by using primer $63 \mathrm{~F}$ for amplification reactions in an ABI 3700 system analyzer (Macrogen, Seoul, Korea).

\section{Data analysis}

All statistical analyses were performed with the packages vegan (Oksanen et al., 2007), labdsv (Roberts, 2006) and BiodiversityR (Kindt and Coe, 2005) for the program R (R Development Core Team, 2007). T-RFLP profiles were analyzed using the IBEST tools (Abdo et al., 2006) and T-Align software (Smith et al., 2005). Data from MspI and HhaI were combined and ordered by nonmetric multidimensional scaling (NMDS) with Wisconsin transformation and Bray-Curtis index (Legendre and Legendre, 1998), and correlations between the ordination axes and environmental variables were calculated. Soil variables were ordered by principal components analysis on the correlation matrix and correlation with NMDS ordination was calculated by Procrustes analysis (Cox and Cox, 2001). The effect of land use on soil attributes was also tested by an analysis of similarity. Distance decay analyses between community similarity and edaphic and geographic variables were also calculated and the significance of correlations was tested by Mantel's tests. The contribution of soil attributes, geographic distance and land use, as well as interactions between them, was estimated by variation partition analysis, with Hellinger transformed data (Peres-Neto et al., 2006). $16 \mathrm{~S}$ rRNA gene sequences were analyzed with RDP tools (release 9.56) (Cole et al., 2007) and the chimeras removed if detected with Bellerophon (with the Huber-Hugenholtz correction), Mallard, Chimera Check or Pintail (Maidak et al., 1999; Huber et al., 2004; Ashelford et al., 2005, 2006). Alignments were edited manually and with GBlocks (Castresana, 2000). Nucleotide substitution models were selected by using PAUP* version $4.0 \mathrm{~b} 10$ (Swofford, 2000) and ModelTest (Posada and Crandall, 1998), and phylogenies were constructed with the Tamura Ney model plus gamma correction and the neighbor-joining algorithm by using MEGA version 4.0 (Tamura et al., 2007). A matrix of operational taxonomic units defined at the level of $3 \%$ of dissimilarity (Schloss and Handelsman, 
2005) was submitted to clustering and redundancy analyses. Indicator species were detected by using the indicator value index (Dufrêne and Legendre, 1997) and Renyi diversity profiles were built to rank communities according to diversity (Kindt and Coe, 2005).

\section{Results}

T-RFLP data analysis

NMDS analysis of the T-RFLP profiles showed that some bacterial communities differed in structure and that these differences are related to land use and changes in several soil attributes, especially those linked to soil acidity, such as $\mathrm{pH},\left[\mathrm{Al}^{3+}\right]$, potential acidity and base saturation (Figure 1a and Supplementary Tables S3 and S4). Primary forest and old secondary forest communities were related to high soil acidity and were similar even when the sampling sites were several kilometers apart. In contrast, some crop communities are related to low
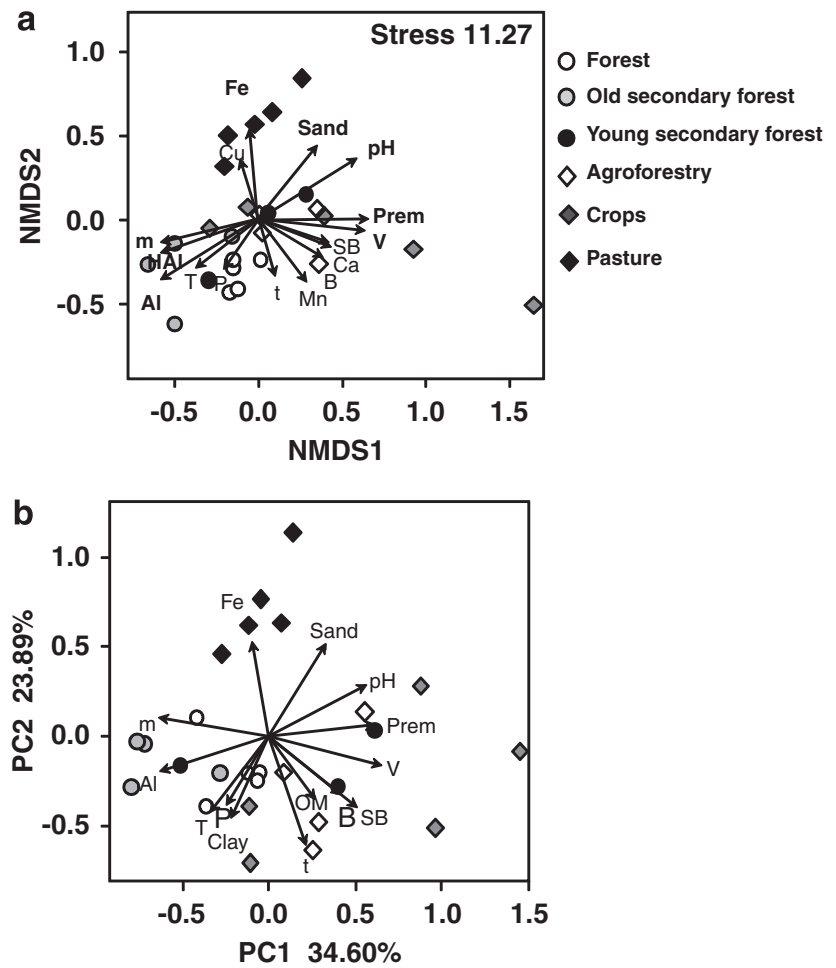

Figure 1 Nonmetric multidimensional scaling and principal component analyses of sampling points. (a) Nonmetric multidimensional scaling ordination of sampling points based on the structure of soil bacterial communities as determined by terminal restriction fragment length polymorphism (T-RFLP) analysis. The most significant variables are showed in boldface (red). (b) Principal components analysis of sampling points based on soil attributes only. Vectors represent significant environmental variables $(P<0.05)$. Each vector points to the direction of increase for a given variable and its length indicates the strength of the correlation between the variable and the ordination scores. V, base saturation; SB, sum of bases; Prem, remnant phosphorus; HAl, potential acidity; $\mathrm{m}$, Al saturation; T, potential cation exchange capacity (CEC); $t$, effective CEC. A full color version of this figure is available at The ISME Journal online. soil acidity and higher nutrient concentrations. Agroforestry communities are related to intermediate values of the soil attributes and crop and young secondary forest communities do not constitute well-defined groups, which agrees with their high variability in age and vegetation. Pasture communities were clearly separated from others and are related to higher $\mathrm{Fe}$ and $\mathrm{Cu}$ concentrations. Similar environmental gradients were detected and a similar grouping of samples is observed when samples were ordered based on soil attributes only (Figure 1b). Furthermore, a significant correlation between these two ordinations was observed, as determined by Procrustes analysis $(76.3 \%, P<0.001)$. A significant effect of land use on the soil attributes is detected by an analysis of similarities $(R=0.394, P<0.001)$ and by redundancy analysis as well when soil attributes are the response variables (data not shown).

A significant trend of decay in community similarity with edaphic distances was observed $\left(R^{2}=0.523\right)$, indicating that bacterial communities tend to be more similar in soils with higher similarity in their attributes (Supplementary Figure S3). The correlation between edaphic factors and community structure accounts for about $31 \%$ of the observed variation in the data (Figure 2) as indicated by variation partitioning analysis. Similarly, interactions between edaphic and other environmental factors were also significant, although they explain a small fraction of the variation. The direct influence of geographic distance and land use alone is not statistically significant, but the interaction between the two was significant. This may be a result of the geographic distribution of land use, which is not random in the area. About half of the variation $(54 \%)$ was due to undetected factors.

\section{$16 S$ rRNA gene clone library analysis}

We recovered 654 partial sequences of the $16 \mathrm{~S}$ rRNA genes from primary forest, old secondary forest, pasture and crop soils. These sequences were assigned to Acidobacteria $(38.8 \%)$, Actinobacteria $(6.1 \%)$, Bacteroidetes $(8.3 \%)$, Chloroflexi $(0.3 \%)$, Firmicutes (2.4\%), Gemmatimonadetes $(0.8 \%)$ and Proteobacteria $(36.2 \%)$, including representatives of the classes $\alpha, \beta, \gamma$ and $\delta$ of Proteobacteria. Of these sequences, $7 \%$ could not be classified to phyla. Phylogenetic analysis revealed clear differences in community composition linked to land use (Figure 3) and the clearest differences were found with the Bacteroidetes, Actinobacteria, Firmicutes and Proteobacteria.

Bacteroidetes were mostly found in crop and pasture soils. In contrast, Firmicutes were found in the primary forest and old secondary forest only. Nearly half of the Actinobacteria sequences are from old secondary forest, whereas the other half was evenly distributed among other land use types. Almost half of the Alphaproteobacteria sequences were from crops. Some clades inside this class had 


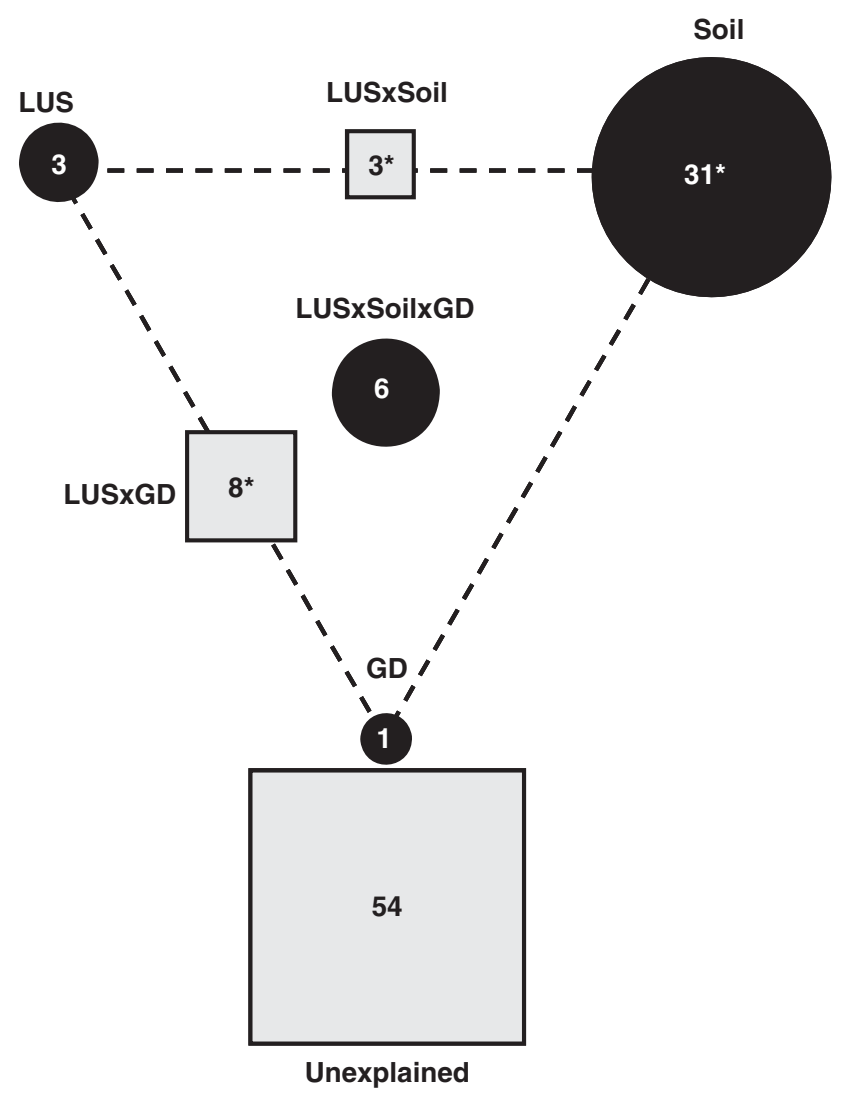

Figure 2 Partitioning analysis of the variation in bacterial community structure into edaphic (Soil), geographic distance (GD) and land use (LUS) components. Circles on the edges of the triangle show the percentage of variation explained by each factor alone. The percentage of variation explained by interactions between two or three of the factors is shown as squares on the sides and as a circle in the center of the triangle. The unexplained variation is depicted in the square on the bottom. The size of circles and squares is proportional to the variance explained. Significant values are marked with an asterisk. Some fractions shown cannot be tested for significance.

distributions that corresponded to land use. For example, Rhodoplanes was found mainly in the primary forest, old secondary forest and pasture, whereas several Brevundimonas-related sequences were found in one of the crop samples. Most Betaproteobacteria were from primary forest. Burkholderia was found mainly in the primary forest and Massilia in pasture and crops. In Gammaproteobacteria, several sequences are from primary forest and old secondary forest and belong to the family Xanthomonadaceae, and Deltaproteobacteria sequences were found mainly in the pasture. The majority of the Acidobacteria sequences belong to group I, which was a dominant group in all samples (Supplementary Figure S4). Group III was found in forest and pasture soils, and group VI was more abundant in crop soils, especially in sample C19, where few Acidobacteria sequences were obtained compared to the other environments.

Some sequences at finer taxonomic levels were indicators of environmental conditions by indicator species analysis. Arthrobacter and Bradyrhizobium were widespread among land use systems whereas sequences belonging to Sphingomonadaceae, Sphingobacteriales and Acidobacteria (group I) were related to pasture, and an uncultured Acidobacteria group I and Rhodoplanes were both related to primary forest and old secondary forest (Supplementary Figure S5 and Table S5).

Operational taxonomic units were defined at the level of $3 \%$ of dissimilarity. They clustered according to differences in $\mathrm{pH}$ and $\left[\mathrm{Al}^{3+}\right]$ (Figure 4), confirming soil acidity as an important factor determining bacterial community structure. Primary forest and old secondary forest communities are again the most similar, as observed by T-RFLP analysis, and form one of the main groups in the dendrogram. These soil samples have the lowest $\mathrm{pH}$ among the studied samples. Another group is formed by pasture and crop samples, which have intermediate $\mathrm{pH}$.

\section{Diversity measures}

Renyi diversity profiles were built with sequence data to rank communities according to diversity. Ranking based on these profiles is preferred to ranking based on single indices because rank order may change when different indices are used (Kindt and Coe, 2005). When curves for two communities intersect, this means that they cannot be ranked.

We found that pasture communities (P82 and P84) and one crop community (C27) are the most diverse (Figure 4). Old secondary forest (SF81 and SF90) and one forest community presented intermediate diversity. Finally, one forest (F10) and one crop community (C19) were identified as the least diverse. Interestingly, communities with similar levels of diversity generally were also more similar in composition. Communities P82, P84 and C27 formed a group in the dendrogram depicted in Figure 4, as well as communities SF81, SF90 and F16. Exceptions were communities F10 and C19.

\section{Discussion}

Our results show that differences in bacterial community structure in the studied soils are significantly correlated to changes in soil attributes, especially those linked to soil acidity and nutrient concentration, showing soil attributes to be an important factor affecting community structure. Those changes in the soil attributes were linked to land use and the same environmental gradients could be detected when bacterial or soil chemical data were used for ordination, indicating that the land use effect was enacted through changes in soil attributes. Because soil type is the same for our sites (Inceptisols are the predominant soil class), we can assume that land use is the main factor leading to changes in the soil attributes. We cannot exclude the 
a
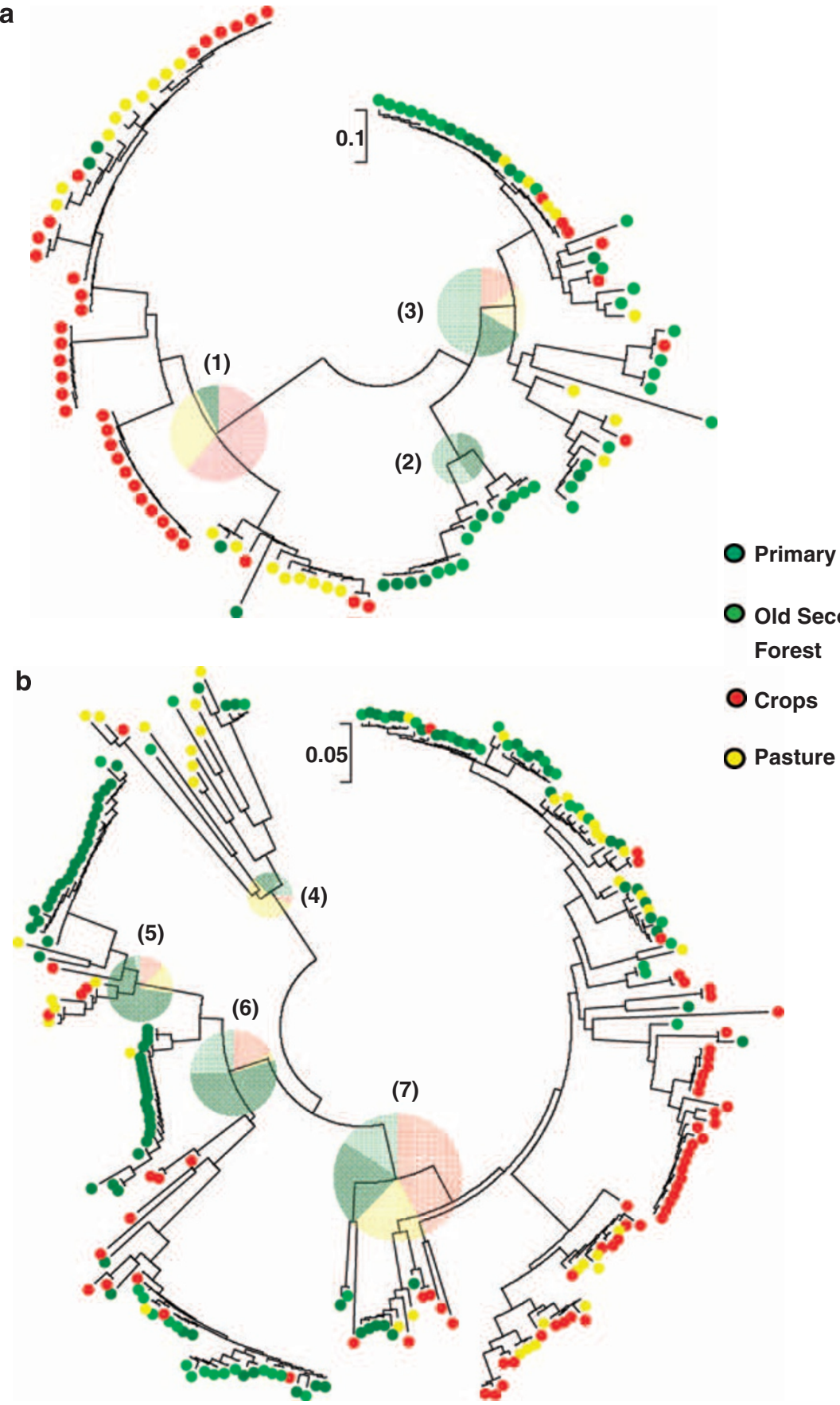

Figure 3 Phylogenetic relationships among bacterial sequences (circles) and their origin (color). Numbers on pies identify clades of Bacteroidetes (1); Firmicutes (2); Actinobacteria (3); and $\delta$ (4), $\beta$ (5), $\gamma$ (6) and $\alpha$ (7) Proteobacteria. Pies indicate the proportion of sequences into each one of these clades and their size is proportional to the number of sequences included therein. Phylogenies were estimated by neighbor joining with the TrN model and $\gamma$ correction $(\alpha=0.390$ for $\mathbf{a}$ and $\alpha=0.362$ for $\mathbf{b})$. Trees are unrooted. The scale bar represents changes per nucleotide.

possibility that soil organisms are affecting these attributes, but we can assume a primary land use effect based on what is known about slash-and-burn agriculture.

In slash-and-burn agriculture, soil attributes change as a consequence of the deposition of ash from the burned vegetation and increased rates of organic matter decomposition (Juo and Manu, 1996). Over time, nutrients are depleted and these attributes tend to return to their previous state. Our results show that bacterial community composition changes accordingly. Community structure was clearly altered when crops or pasture were introduced but tended to become more similar to the primary forest when the forest was allowed to regrow. This indicates that the intensity of slashand-burn agriculture practiced in the studied areas was not sufficient to significantly impact soil 


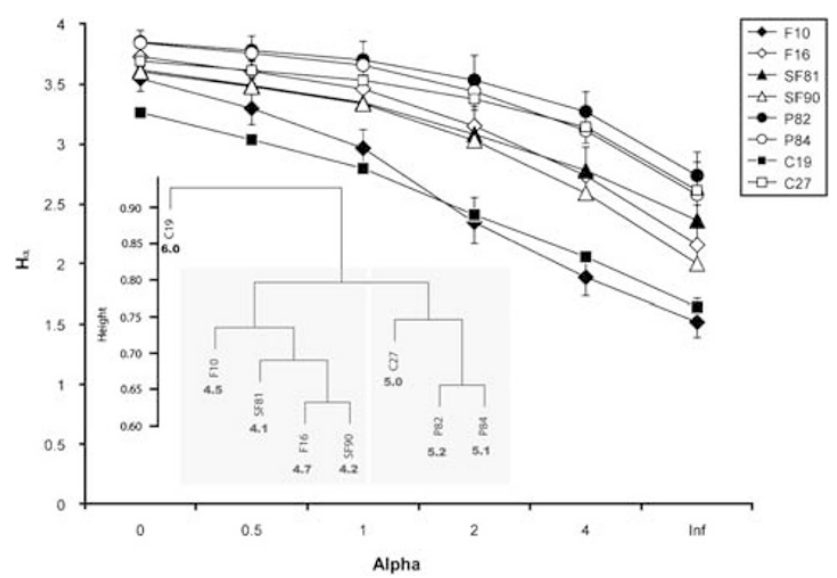

Figure 4 Renyi diversity profiles of soil bacterial communities. The $x$ - and $y$-axes show, respectively, the $\alpha$ value of the Renyi's formula and their associated Renyi diversity profile values $\left(\mathrm{H}_{\alpha}\right)$. Renyi profile values at the scales of 0, 1, 2 and infinite are related to species richness, Shannon diversity index, Simpson diversity index and Berger-Parker index, respectively (see Kindt and Coe, (2005) for more information). Confidence intervals are represented by the $2.5 \%$ and $97.5 \%$ percentile values obtained after 100 permutations of the data. The inset depicts an average linkage clustering dendrogram based on the Bray-Curtis distances among bacterial communities. Numbers in boldface indicate the $\mathrm{pH}$ of each soil sample and the rectangles mark the main groups identified in the dendrogram. F10 and F16, primary forest; SF81 and SF90, old secondary forest; P82 and P84, pasture; C19 and C27, crops. A full color version of this figure is available at The ISME Journal online.

bacterial communities. These sites are surrounded by large forest areas, which should serve as an inoculum source for colonization of previously deforested areas, should that be a factor.

Our results are consistent with studies in nontropical areas where land use and soil attributes were found as important factors determining the diversity and structure of bacterial communities (Hartman et al., 2008; Wakelin et al., 2008). We found strong correlations between community structure and variables linked to soil acidity (Figure 1 and Supplementary Table S3), indicating soil acidity as an important factor causing changes in soil community structure. Fierer and Jackson (2006) found $\mathrm{pH}$ as the main factor correlated with bacterial diversity and community similarity in a continental scale, and Hartman et al. (2008) and Wakelin et al. (2008) also found that $\mathrm{pH}$ affected diversity, composition and function of bacterial communities in wetland and Australian agricultural soils. $\mathrm{pH}$ is a master variable in the soil environment and it is related to changes in other soil attributes, such as $\mathrm{Al}$ concentration and nutrient availability (McBride, 1994). Al toxicity has long been known to affect microbes as well as plants in tropical soils (Wood, 1995; Joner et al., 2005), and has been especially problematic in some regions for effective Rhizobium-legume symbioses (Hungria and Vargas, 2000). Soils in the studied area are rich in $\mathrm{Al}$ due to the presence of minerals with Al interlayers (Marques et al., 2002). Hence, it is not surprising that $\mathrm{pH}$ and Al would covary and correlate with microbial community changes in these more native soils.

The above findings indicate that the soil environment is a key factor in defining the structure of communities, whether under natural (Fierer and Jackson, 2006) or under anthropic conditions, including slash-and-burn (our sites) and conventional agriculture (Hartman et al., 2008; Wakelin et al., 2008). Although the slash-and-burn system has important differences from the larger-scale land use changes now underway in other areas of the Amazon, the effects of disturbance and particular attributes that we found may still be predictive for the current land use changes.

It is noteworthy that bacterial communities responded rapidly to changes due to cultivation and forest recovery. The crop areas were relatively young, one year since the beginning of the current cultivation. Nevertheless, we observed a significant difference in the structure of their soil communities. It is also noteworthy that there was not a reduction in diversity when the forest soil was converted to pasture or crops. In fact, pasture communities seem to be even more diverse than those of long-standing primary forest.

The phyla we found are typical of most soils, including soils of the eastern and western Amazon (Borneman and Triplett, 1997; Kim et al., 2007). Distribution of sequences among and within phyla differed among land use systems, indicating a possible effect of land use. Acidobacteria and Proteobacteria were the most abundant phyla. Clostridium was present only in the primary forest and old secondary forest, confirming previous Amazon soil studies (Borneman and Triplett, 1997). We found Acidobacteria group III sequences in the acidic forest soil ( $\mathrm{pH} 4.5$ and 4.7) as well as pasture soils (pH 5.2 and 5.1), whereas Barns et al. (1999) did not find members of this group in acid soils and sediments $(\mathrm{pH}<6)$ and suggested neutrophily to be a possible feature of this group. The Acidobacterium families, however, are quite diverse and such phenotypic differences could be expected within these genetically diverse groups.

On the basis of these findings, we conclude that differences observed in bacterial community structure and composition are related to land use, likely through the effects of soil attributes, especially those related to soil acidity. The conversion of forest to pasture and crops did not reduce bacterial diversity, and the growth of secondary forest restored a community similar to that of the primary forest.

\section{Acknowledgements}

We acknowledge the Global Environmental Facility/United Nations Environment Programme (GEF/UNEP project CSM-BGBD/GF2715-02) and the Center for Microbial Ecology (Michigan State University) for financial support, the Capes foundation for the "sandwich" fellowship 
provided to Ederson da C Jesus and CNPq for FMS Moreira's research fellowship. This publication presents part of the findings of the international project Conservation and Management of Below-Ground Biodiversity implemented in Brazil, Cote d'Ivoire, India, Indonesia, Kenya, Mexico and Uganda. This project is coordinated by the Tropical Soil Biology and Fertility Institute of CIAT (TSBF-CIAT with cofinancing from the Global Environmental Facility and implementation support from the United Nations Environment Program). Views expressed in this publication are those of the authors and do not necessary reflect those of the authors' organization, the United Nations Environment Programme and the Global Environmental Facility.

\section{References}

Abdo Z, Schüette UME, Bent SJ, Willians CJ, Forney LJ, Joyce P. (2006). Statistical methods for characterizing diversity of microbial communities by analysis of terminal restriction fragment length polymorphisms of 16S rRNA genes. Environ Microbiol 8: 929-938.

Ashelford KE, Chuzhanova NA, Fry JC, Jones AJ, Weightman AJ. (2005). At least 1 in 20 16S rRNA sequence records currently held in public repositories is estimated to contain substantial anomalies. Appl Environ Microbiol 71: 7724-7736.

Ashelford KE, Chuzhanova NA, Fry JC, Jones AJ, Weightman AJ. (2006). New screening software shows that most recent large $16 \mathrm{~S}$ rRNA gene clone libraries contain chimeras. Appl Environ Microbiol 72: 5734-5741.

Barns SM, Takala SL, Kuske CR. (1999). Wide distribution and diversity of members of the bacterial kingdom Acidobacterium in the environment. Appl Environ Microbiol 65: 1731-1737.

Borneman J, Triplett EW. (1997). Molecular microbial diversity in soils from Eastern Amazonia: evidence for unusual microorganisms and microbial population shifts associated with deforestation. Appl Environ Microbiol 63: 2647-2653.

Buckley DH, Huangyutitham V, Nelson TA, Rumberger A, Thies JE. (2006). Diversity of Planctomycetes in soil in relation to soil history and environmental heterogeneity. Appl Environ Microbiol 72: 4522-4531.

Castresana J. (2000). Selection of conserved blocks from multiple alignments for their use in phylogenetic analysis. Mol Biol Evol 17: 540-552.

Coelho MR, Fidalgo ECC, Araújo F de O, dos Santos HG, Mendonça Santos ML et al. (2005). Solos das áreas-piloto do Projeto BiosBrasil (Conservation and Sustainable Management of Below Ground Biodiversity: Phase I), Município de Benjamim Constant, Estado do Amazonas [recurso eletrônico] Rio de Janeiro: Embrapa Solos. - (Boletim de pesquisa e desenvolvimento/Embrapa Solos, ISSN 1678-0892; 67).

Cole JR, Chai B, Farris RJ, Wang Q, Kulam-Syed-Mohideen AS, McGarrell DM et al. (2007). The ribosomal database project (RDP-II): introducing myRDP space and quality controlled public data. Nucleic Acids Res 35(Database issue): D169-D172.

Cox TF, Cox MAA. (2001). Monographs on statistics and applied probability. Multidimensional Scaling, Vol 88. 2nd edn. Chapman \& Hall/CRC: Boca Raton.

da Silveira EL, Pereira RM, Scaquitto DC, Pedrinho EAN, Val-Moraes SP, Wickert E et al. (2006). Bacterial diversity of soil under eucalyptus assessed by $16 \mathrm{~S}$ rDNA sequencing analysis. Pesqui Agropecu Bras 41: 1507-1516.

Dufrêne M, Legendre P. (1997). Species assemblages and indicator species: the need for a flexible asymmetrical approach. Ecol Monogr 67: 345-366.

Egert M, Friedrich MW. (2005). Post-amplification Klenow fragment treatment alleviates PCR bias caused by partially single-stranded amplicons. J Microbiol Methods 61: 69-75.

Fidalgo ECC, Coelho MR, Araújo F de O, Moreira FMS, Santos HG, dos Santos M de LM et al. (2005). Levantamento do uso e cobertura da terra de seis áreas amostrais relacionadas ao projeto BiosBrasil (Conservation and Sustainable Management of Below-Groud Biodiversity: Phase I), Município de Benjamin Constant (AM). Rio de Janeiro: Embrapa. (Embrapa Solos. Boletim de Pesquisa e Desenvolvimento). Available at: www.biosbrasil.ufla.br, Accessed in 10 Nov. 2006.

Fierer N, Jackson RB. (2006). The diversity and biogeography of soil bacterial communities. Proc Natl Acad Sci USA 103: 626-631.

Hartman WH, Richardson CJ, Vilgalys R, Bruland GL. (2008). Environmental and anthropogenic controls over bacterial communities in wetland soils. Proc Natl Acad Sci USA 105: 17842-17847.

Huber T, Faulkner G, Hugenholtz P. (2004). Bellerophon: a program to detect chimeric sequences in multiple sequence alignments. Bioinformatics 20: 2317-2319.

Hungria M, Vargas MAT. (2000). Environmental factors affecting N2 fixation in grain legumes in the tropics, with an emphasis on Brazil. Field Crops Res 65: 151-164.

Joner EJ, Eldhuset TD, Lange H, Frostegård A. (2005). Changes in the microbial community in a forest soil amended with aluminum in situ. Plant Soil 275: 295-304.

Juo AS, Manu RA. (1996). Chemical dynamics in slash-andburn agriculture. Agricult Ecosys Environ 58: 49-60.

Kim J-S, Sparovek G, Longo RM, de Melo WJ, Crowley D. (2007). Bacterial diversity of terra preta and pristine forest soil from the Western Amazon. Soil Biol Biochem 39: 684-690.

Kindt R, Coe R. (2005). Tree Diversity Analysis. A Manual and Software for Common Statistical Methods and Biodiversity Studies. World Agroforestry Centre. (ICRAF): Nairobi.

Legendre P, Legendre L. (1998). Numerical Ecology (2nd English edn.) Elsevier Science BV: Amsterdam.

Maidak BL, Cole JR, Parker Jr CT, Garrity GM, Larsen N, Li B et al. (1999). A new version of the RDP (Ribosomal Database Project). Nucleic Acids Res 27: 171-173.

Marchesi JR, Sato T, Weightman AJ, Martin TA, Fry JC, Hiom SJ et al. (1998). Design and evaluation of useful bacterium-specific PCR primers that amplify genes coding for bacterial 16S rRNA. Appl Environ Microbiol 642: 795-799.

Marques JJ, Teixeira WG, Schulze DG, Curi N. (2002). Mineralogy of soils with unusually high exchangeable Al from the western Amazon Region. Clay Miner 37: 651-661.

McBride MB. (1994). Environmental Chemistry of Soils. Oxford University Press: New York.

Nüsslein K, Tiedje JM. (1999). Soil bacterial community shift correlated with change from forest to pasture vegetation in a tropical soil. Appl Environ Microbiol 65: $3622-3626$. 
Oksanen J, Kindt R, Legendre P, O’Hara RB. (2007). Vegan: Community Ecology Package version 1.8-6. http:// cran.r-project.org/.

Osborn AM, Moore ERB, Timmis KN. (2000). An evaluation of terminal-restriction fragment length polymorphism T-RFLP analysis for the study of microbial community structure and dynamics. Environ Microbiol 2: 39-50.

Pereira RM, da Silveira EL, Scaquitto DC, Pedrinho EAN, Val-Moraes SP, Wickert E et al. (2006). Molecular characterization of bacterial populations of different soils. Braz J Microbiol 37: 439-447.

Peres-Neto PR, Legendre P, Dray S, Borcard D. (2006). Variation partitioning of species data matrices: estimation and comparison of fractions. Ecology 87: 2614-2625.

Posada D, Crandall KA. (1998). Modeltest: testing the model of DNA substitution. Bioinformatics 14: 817-818.

Quirino B, Pappas GJ, Tagliaferro AC, Collevatt RG, Leonardecz Neto E, da Silva RSS et al. (2009). Molecular phylogenetic diversity of bacteria associated with soil of the savanna-like Cerrado vegetation. Microbiol Res 164: 59-70.

$\mathrm{R}$ Development Core Team (2007). R: A Language and Environment for Statistical Computing. R Foundation for Statistical Computing: Vienna, Austria. ISBN: 3-900051-07-0, http://www.R-project.org.

Roberts DW. (2006). labdsv: Laboratory for Dynamic Synthetic Vegephenomenology. $\mathrm{R}$ package version 1.2-2, http://ecology.msu.montana.edu/labdsv/R.

Schloss PD, Handelsman J. (2005). Introducing DOTUR, a computer program for defining operational taxonomic units and estimating species richness. Appl Environ Microbiol 71: 1501-1506.

Smith CJ, Danilowicz BS, Clear AK, Costello FJ, Wilson B, Meijer WG. (2005). T-Align, a web-based tool for comparison of multiple terminal restriction fragment length polymorphism profiles. FEMS Microbiol Ecol 54: $375-380$.

Steenwerth KL, Jackson LE, Calderón FJ, Stromberg MR, Sow KM. (2002). Soil microbial community composition and land use history in cultivated and grassland ecosystems of coastal California. Soil Biol Biochem 34: 1599-1611.

Swift MJ, Andrén O, Brussaard L, Briones M, Couteaux M-M, Ekschmitt $\mathrm{K}$ et al. (1998). Global change, soil biodiversity, and nitrogen cycling in terrestrial ecosystems: three case studies. Glob Change Biol 4: 729-743.

Swofford DL. (2000). PAUP*: Phylogenetic Analysis Using Parsimony (and Other Methods), Version 4. Sinauer Associates: Sunderland, MA.

Tamura K, Dudley J, Nei M, Kumar S. (2007). MEGA4: Molecular Evolutionary Genetics Analysis MEGA software version 4.0. Mol Biol Evol 24: 1596-1599.

Wakelin SA, Macdonald LM, Rogers SL, Gregg AL, Bolger TP, Baldock JA. (2008). Habitat selective factors influencing the structural composition and function capacity of microbial communities in agricultural soils. Soil Biol Biochem 40: 803-813.

Wieland G, Neumann R, Backhaus H. (2001). Variation of microbial communities in soil, rhizosphere, and rhizoplane in response to crop species, soil type and crop development. Appl Environ Microbiol 67: 5849-5854.

Wood M. (1995). Mechanism of aluminum toxicity to soil bacteria and possible ecological applications. Plant Soil 171: 63-69.

Yin B, Crowley D, Sparovek G, de Melo WJ, Borneman J. (2000). Bacterial functional redundancy along a soil reclamation gradient. Appl Environ Microbiol 66: 4361-4365.

Supplementary Information accompanies the paper on The ISME Journal website (http://www.nature.com/ismej) 